PENGKAJIAN PEWILAYAHAN KOMODITAS GAMBIR (Uncaria gambir Roxb.) DI KABUPATEN PAKPAK BHARAT SKALA $1: 50.000$

\title{
ASSESSMENT OF COMMODITIES AREA GAMBIER (Uncaria gambir Roxb.) IN PAKPAK BHARAT SCALE $1: 50.000$
}

\section{Lukas Sebayang}

Balai Pengkajian Teknologi Pertanian Sumatera Utara, Medan- 20143

Corresponding author : mabayang2001@yahoo.com

\begin{abstract}
Gambier (Uncaria gambier Roxb.) is a cultivated plant regeneration in Pakpak Bharat. Gambir extract benefits as well as the pharmaceutical industry and traditional is quite interested so that market opportunities gambier quite open for the domestic market and abroad. Land potential and development opportunities gambir high enough, it is in the use of plantation area of 1,224 ha and optimization of dry land area of 16 049, 6 hectares (Pakpak Bharat in Figures, 2013). Gambier development in Pakpak Bharat tends to increase, so it is necessary to study the suitability of land to see the direction of the development of the appropriate location. This assessment was conducted by using ALES (Automated Land Evaluation System). SDPLE (Standard Procedure for Land Evaluation) data was imported to ALES program. Land evaluation result was show in spatial form. This form made by imported tabulation data to GIS (Geographical Information System) form. Suitability land maps (scale $1: 250.000$ ) present based on each commodities by ArcView program.
\end{abstract}

Key words : Commodity area, gambier, Pakpak Bharat

\section{ABSTRAK}

Tanaman gambir (Uncaria gambir Roxb.) merupakan tanaman yang dibudidayakan secara regenerasi atau turun temurun di Kabupaten Pakpak Bharat. Manfaat ekstrak gambir sebagai bahan industri farmasi maupun tradisional cukup diminati sehingga peluang pasar gambir cukup terbuka baik pasar dalam negeri maupun luar negeri. Potensi lahan dan peluang pengembangan gambir cukup tinggi, hal ini dalam penggunaan lahan perkebunan seluas 1.225 ha dan optimalisasi lahan kering seluas 16.049,6 Ha (Pakpak Bharat Dalam Angka, 2013). Pengembangan komoditas gambir di Kabupaten Pakpak Bharat cenderung terus meningkat, sehingga perlu dilakukan pengkajian pewilayahan komoditas untuk kesesuaian lahan untuk melihat arah lokasi pengembangan yang sesuai. Pengkajian ini dilakukan dengan memanfaatkan program ALES (Automated Land Evaluation System). Pelaksanaan komputasi dilakukan dengan mengimport data SDPLE (Standard Procedure for Land Evaluation) atau data yang sudah tersedia dalam format Excell ke program ALES. Penyajian hasil evaluasi lahan dalam wujud spasial atau peta dilakukan dengan cara mengimport data tabulasi kedalam format GIS (Geographical Information System). Penyajian peta kesesuaian lahan skala 1 : 50.000 dibuat berdasarkan jenis komoditas pertanian dengan menggunakan program ArcView.

Kata kunci : Pewilayahan komoditas, gambir, Pakpak Bharat 


\section{PENDAHULUAN}

Pakpak Bharat merupakan pemekaran dari Kabupaten Dairi pada tahun 2003 dengan jumlah penduduk pada tahun 2010 sebanyak 40.505 jiwa terdiri dari 8.992 rumah tangga. Kabupaten Pakpak Bharat terletak di $2^{0} 15^{\prime} 00^{\prime \prime}-$ $3^{0} 32^{\prime} 00^{\prime}$ " LU dan $96^{\circ} 00^{\prime}-98^{0} 31$ ' BT dan luas wilayah adalah $1.218,30 \mathrm{~km}^{2}$ yang terdiri dari 8 Kecamatan dan 52 Desa.

Di subsektor perkebunan, pada tahun 2013 ada tiga komoditas andalan dengan luas dan produksi terbesar, yaitu Gambir, Kopi Arabika dan Kelapa Sawit. Pada tahun 2012 luas areal tanaman gambir sebesar 1.225 ha dengan produksi 1.452 t (Pakpak Bharat Dalam Angka, 2013). Bila dibandingkan Provinsi Sumatera Barat, Pakpak Baharat jauh lebih kecil luas tanam dan produksinya yaitu Kabupaten Limapuluh Kota , Pesisir Selatan dan daerah tibgkat II lainnya. Kabupaten Lima Puluh Kota sebanyak 11.937 ha dengan produksi $7.379 \mathrm{t}$ pertahun. Kabupaten Pesisir Selatan sebanyak 2.469 ha dengan produksi $688 \mathrm{t}$ pertahun dan kabupaten lainnya seluas 175 ha yang sebagian besar belum berproduksi (Dhalimi, 2006). Sesuai dengan kebijaksaan Pemerintah Daerah di tahun mendatang, Pakpak Bharat akan menjadi penghasil gambir terbesar melalui Program sejuta Gambir. Namun informasi mengenai ketersediaan lahan Gambir untuk pengembangan ke depan masih sangat terbatas. Oleh sebab pada tahun 2006, Pemerintahaan Kabupaten Pakpak Bharat bekerjasama BPTP Sum.Utara melakukan pengkajian kesesuaian lahan untuk tanaman Gambir di Kabupaten Pakpak Bharat. Kondisi topografi lahan daerah ini sebagian besar berbukit-bukit hingga bergunung-gunung. Wilayah berada pada ketinggian 300-1.500 m dpl. Jumlah curah hujan selama tahun 2010 adalah $3161 \mathrm{~mm}$ dengan rata-rata curah hujan bulanan 263 $\mathrm{mm} / \mathrm{bulan}$ dan rata-rata hari hujan 13 hari/bulan. Berdasarkan keadaan topografi lahannya terdiri dari lahan datar $\left(\mathrm{km}^{2}\right)$, landai $\left(3.348 \mathrm{~km}^{2}\right)$, miring $\left(28.016 \mathrm{~km}^{2}\right)$ dan terjal $\left(84.070 \mathrm{~km}^{2}\right)$ dengan jenis tanah alluvial, glei humus, organosol (512 ha), podsolik coklat/kelabu (91.136 ha), podsolik coklat (3.552 ha), latosol/regosol (3.072 ha) (BPTP Sumut, 2006).

Penggunaan lahan di daerah ini didominasi oleh lahan kering 114.444 ha, sedangkan lahan basah (sawah) seluas 1.206 ha. Peruntukan lahan kering lebih banyak adalah untuk hutan. Sumber mata pencarian utama masyarakat di daerah ini di dominasi system pertanian lahan kering yaitu tanaman perkebunan atau tanaman campuran seluas 40.121 ha, sedangkan lahan persawahan hanya seluas 1.622 ha. Tanaman perkebunan yang dominan adalah Gambir, Karet, Coklat, Kelapa Sawit, Kopi dan Nilam (Pakpak Bharat Dalam Angka, 2011). Tanaman Gambir dijumpai di semua kecamatan dan yang paling luas terdapat di ke Kecamatan $\mathrm{Si}$ Telu Tali Urang (STTU) Jehe seluas 582 ha $(55 \%), 117$ ha $(11 \%)$ di Kerajaan dan 114 ha $(11 \%)$ di Tinada. Produksi getah gambir kering yang dihasilkan dari Pakpak Bharat pada tahun 2010 adalah sebanyak 1.523 t. Sentra produksi Gambir terdapat di Desa Bandar Baru, Kaban Tengah, Mbinalum, Malum Perolihen (Kec.STTU Jehe), Aornakan, Simerpara (Kec.PGGS), Mahala (Kec.Tinada), Majanggut I, Majanggut II (Kec.Kerajaan) seperti terlihat pada Tabel 1. 
Tabel 1. Luas serta produksi gambir di Kabupaten Pakpak Bharat

\begin{tabular}{llrr}
\hline No & \multicolumn{1}{c}{ Kecamatan } & Luas Area (ha) & Produksi (t) \\
\hline 1 & Salak & 92 & 51 \\
2 & Sitelu Tali Urang Jehe & 589 & 832 \\
3 & Pagindar & 33 & 13 \\
4 & Sitelu Tali Urang Julu & 21 & 16 \\
5 & Pergeteng Geteng Sengkut & 170 & 140 \\
6 & Kerajaan & 115 & 154 \\
7 & Tinada & 118 & 141 \\
8 & Siempat Rube Jumlah & 87 & 105 \\
& $\quad 1.225$ & 1.452 \\
\hline
\end{tabular}

Sumber : Pakpak Bharat Dalam Angka, 2013

Peta arahan komoditas dan kesesuaian lahan untuk tanaman gambir dan komoditas lainnya di Kabupaten Pakpak Bharat telah dihasilkan oleh BPTP Sum.Utara (Ibrahim et.al, 1999; BPTP Sumut 2006). Peta kesesuaian lahan tersebut dengan skala $1: 50.000$ didasarkan pada data hasil evaluasi lahan untuk berbagai komoditas pertanian, baik berupa data tabular maupun data spasial (peta kesesuaian lahan). Sedangkan evaluasi lahan didasarkan pada karakteristik lahan yang bersumber dari data/peta satuan lahan hasil analisis terrain yang telah dilengkapi dengan data tanah dan iklim, serta sosial ekonomi. Penyajian hasil evaluasi lahan dalam wujud spasial atau peta dilakukan dengan cara mengimpor data tabulasi hasil ALES ke dalam format GIS. Penyajian peta kesesuaian lahan dibuat berdasarkan jenis komoditas pertanian yang dikaji dengan menggunakan program ArcView. Untuk Penyusunan peta pewilayahaan komoditas pertanian skala $1: 50.000$, diperlukan hasil evaluasi lahan untuk berbagai komoditas pertanian. Evaluasi lahan didasarkan pada data spasial yaitu peta satuan lahan hasil analisis terrain, dan data tabular berupa data lapangan dan laboratorium dengan menggunakan parameter iklim, terrain dan tanah. Evaluasi lahan dilakukan dengan cara membandingkan (matching) antara karakteristik lahan (land characteristics) dan persyaratan penggunaan lahan (landuse requirements) . Dari hasil evaluasi lahan tersebut dilakukan pewilayahan komoditas pertanian dengan mempertimbangkan aspek-aspek yang berkaitan erat, yaitu : kelas kesesuaian lahan, jenis komoditas unggulan daerah, daya saing dan ekonomi, kondisi social budaya setempat, aksesibilitas dan ketersediaan tenaga kerja setempat. Persyaratan penggunaan lahan komoditi Gambir dapat dilihat pada tabel 2.

\section{BAHAN DAN METODE}

Kegiatan pengkajian ini dilakukan di Kabupaten Pakpak Bharat pada bulan April 2012. Bahan yang digunakan dalam pengkajian ini adalah data sekunder dari instansi terkait, juga digunakan beberapa perangkat lunak (software) seperti ALES (Automated Land Evaluation System), Arc Info dan Arc View serta alat GPS (Global Positioning Systems).

Metode Pelaksanaan

1. Penyusunan Basis Data

(a)Data tabular

Data hasil pengamatan di lapangan dan hasil analisa laboratorium, yang terdiri atas sifat-sifat morfologi tanah, fisik lingkungan, sifat fisik kimia dapat dimasukkan (entry) dalam format basis data tabular melalui program yang sudah tersedia, yaitu Site Horizon Description (SHD), Soil Sample Analysis (SSA) dan Mapping Unit Description (MU) untuk keperluan penyusunan data karakteristik lahan untuk setiap satuan lahan. Data 
tersebut selanjutnya digunakan untuk tujuan evaluasi lahan untuk komoditas pertanian unggulan. Basis data tabular satuan lahan tersebut dapat dihubungkan (linkage) dengan data spasial (peta satuan lahan) dengan fasilitas GIS untuk menampilkan hasil evaluasi lahan berupa peta kesesuaian lahan.

Tabel 2. Persyaratan penggunaan lahan (landuse requirements) komoditi Gambir.

\begin{tabular}{|c|c|c|c|c|}
\hline \multirow{2}{*}{$\begin{array}{c}\text { Persyaratan } \\
\text { penggunaan/karakteristik } \\
\text { lahan }\end{array}$} & \multicolumn{4}{|c|}{ Kelas Kesesuaian Lahan } \\
\hline & S1 & $\mathrm{S} 2$ & S3 & $\mathrm{N}$ \\
\hline \multicolumn{5}{|l|}{ Temperatur (tc) } \\
\hline \multirow[t]{2}{*}{ Temperatur rerata $\left({ }^{\circ} \mathrm{C}\right)$} & $18-22$ & $15-18$ & $25-17$ & $<15$ \\
\hline & & $22-25$ & - & $>27$ \\
\hline \multicolumn{5}{|l|}{ Ketersediaan air (wa) } \\
\hline \multirow[t]{2}{*}{ Curah hujan (mm) } & $2.000-$ & $1.300-2.000$ & $1.000-1.300$ & $<1.000$ \\
\hline & 2.000 & $2.500-3.000$ & $3.000-4.000$ & $>4.000$ \\
\hline \multirow{2}{*}{$\begin{array}{l}\text { Ketersediaan oksigen } \\
\text { (oa) }\end{array}$} & baik, agak & agak & terhambat & Sgt \\
\hline & Baik & terhambat & Agak cepat & Terhambat \\
\hline \multicolumn{5}{|l|}{ Drainase } \\
\hline \multicolumn{5}{|l|}{ Media perakaran (rc) : } \\
\hline Tekstur & h,ah,s,ak & h,ah,s,ak & $\mathrm{k}$ & $\mathrm{k}$ \\
\hline Bahan kasar (\%) & $<15$ & $15-35$ & $35-55$ & $>55$ \\
\hline Kedalam tanah $(\mathrm{cm})$ & $>100$ & $75-100$ & $50-75$ & $<50$ \\
\hline \multicolumn{5}{|l|}{ Gambut : } \\
\hline Ketebalan (cm) & $<60$ & $60-140$ & $140-200$ & $>200$ \\
\hline+ dgn sisipan & $<140$ & $140-200$ & $200-400$ & $>400$ \\
\hline Kematangan & saprik + & $\begin{array}{l}\text { saprik } \\
\text { hemik+ }\end{array}$ & hemik fibrik & fibrik \\
\hline \multicolumn{5}{|l|}{ Rentensi hara (nr): } \\
\hline KTK liat $(\mathrm{cmol})$ & $>16$ & $\leq 16$ & & \\
\hline Kejenuhan basa (\%) & $>50$ & $35-50$ & $<35$ & \\
\hline $\mathrm{pH} \mathrm{H}_{2} \mathrm{O}$ & $5,0-7,0$ & $4,0-5,0$ & $<4,0$ & \\
\hline C-organik (\%) & $>0,4$ & $\leq 0,4$ & & \\
\hline \multicolumn{5}{|l|}{ Toksitas (xc) } \\
\hline Salinitas (ds/m) & $<5$ & $5-8$ & 810 & $>10$ \\
\hline
\end{tabular}

Sumber : BPTP Sumatera Utara (2006)

(b) Data spasial

Peta satuan lahan yang telah disusun berdasarkan hasil analisis terrain dari foto udara perlu dilakukan perbaikan perbaikan delineasi maupun penamaannya berdasarkan hasil pengamatan di lapangan. Perbaikan dapat dilakukan melalui interpretasi kembali foto udara untuk memantapkan hasil dengan dilengkapi data tanah. Peta satuan lahan yang telah diperbaiki dilakukan digitasi dan disimpan dalam basis data spasial. Basis data tabular dan spasial tersebut selanjutnya digunakan sebagai dasar evaluasi lahan untuk berbagai komoditas pertanian. Disamping peta satuan lahan yang disimpan dalam basis data spasial sebagai data pendukung, untuk mengetahui sebaran penggunaan lahan pertanian melalui overlay kedua peta tersebut.

2. Penyusunan Model Evaluasi Lahan Penyusunan model evaluasi lahan (ALES) dilaksanakan melalui tahapan berikut :

a. Menetapkan tipe penggunaan lahan atau LUT (Land Use Type). Adalah jenisjenis penggunaan lahan yang diuraikan 
secara detail menyangkut pengelolaan, masukan yang diperlukan dan keluaran yang diharapkan secara spesifik.

b. Menentukan persyaratan tumbuh tanaman atau LUR (Land Use Requirement) untuk setiap LUT.

c.Memilih karakteristik lahan atau LC (Land Characteristic) setiap LUR untuk masing-masing LUT. Adalah sifat lahan yang dapat diukur atau diestimasi seperti besarnya lereng, kedalaman efektif, drainase, tekstur, reaksi tanah, kejenuhan basa, dan kejenuhan aluminium.

d. Pohon keputusan atau DT (Decision Tree). Adalah metode pengambilan keputusan untuk menentukan kelas kesesuaian lahan secara "hierarchal multi way key". Pengambilan keputusan untuk menentukan kelas kesesuaian lahannya mempunyai hirarki bertingkat dan ditentukan oleh satu atau lebih karakteristik lahan yang mempunyai kaitan erat antara satu dengan yang lainnya.

Prosedur penyusunan model evaluasi lahan secara rinci akan mengacu kepada Standard Procedure for Land Evaluation (Technical Report No. 18, Version 3.0. 1997).

3. Komputasi
Evaluasi lahan dilaksanakan dengan memanfaatkan program ALES (Automated Land Evaluation System). Pengoperasian program ALES sesuai dengan User Manual ALES Version 4.65 (Rositer, 1997). Pelaksanaan komputasi dilakukan dengan mengimport data SDPLE atau data yang sudah tersedia dalam format Excell ke dalam Program ALES.

4. Penyusunan Data

Penyajian hasil evaluasi lahan dalam bentuk spasial atau peta dilakukan dengan cara mengimport data tabulasi ke dalam format GIS. Penyajian peta kesesuaian lahan dibuat berdasarkan jenis komoditas pertanian dengan menggunakan program ArcView. Hasil evaluasi lahan menyajikan kelas kesesuaian lahan untuk komoditas gambir di Kabupaten Pakpak Bharat. Kesesuaian lahan tiap komoditas pada setiap satuan tanah dibedakan menjadi 3 kelas yaitu : sesuai (S), sesuai merjinal (CS) dan tidak sesuai (N). Satuan peta tanah yang berupa asosiasi atau kompleks dapat mempunyai 2 sampai 3 kelas kesesuaian lahan yang berbeda sehingga untuk mempermudah penggunaannya dilakukan penyederhanaan seperti terlihat pada Tabel 3.

Tabel 3. Kriteria Penyederhanaan Kelas Kesesuaian Lahan Komoditas Gambir, Kab. Pakpak Bharat

\begin{tabular}{ll}
\hline Kelas & Uraian \\
\hline Lahan Sesuai (S) & $>75 \%$ lahan sesuai \\
$\mathrm{S}$ & $50-75 \%$ lahan sesuai dan 25-50\% lahan sesuai marjinal \\
$\mathrm{C} / \mathrm{S}$ & $>75 \%$ lahan sesuai marjinal \\
Lahan Sesuai Marjinal (CS) & $50-75 \%$ lahan sesuai marjinal dan 25-50\% lahan tidak \\
$\mathrm{CS}$ & sesuai \\
CS/N & \\
& $>75 \%$ lahan tidak sesuai \\
Lahan Tidak Sesuai (N) & $50-75 \%$ lahan tidak sesuai dan 25-50\% lahan sesuai \\
$\mathrm{N}$ & marjinal \\
N/CS &
\end{tabular}

Sumber : Puslittanak. 2000.

5. Penyajian Hasil

Hasil penyusunan peta satuan lahan

dan peta kesesuaian lahan komoditas gambir disajikan dalam bentuk peta yang dilengkapi dengan naskah laporannya. Format peta mengikuti system proyeksi 
dan koordinat Peta Rupa Bumi, yaitu sistem proyeksi UTM (Universal Transvere Mercator). Skala peta disajikan dalam skala 1 : 250.000. Informasi skala peta dibubuhkan pada peta dalam bentuk skala numeric dan skala gtafis (Environmental System Research Institite.Inc, 1990).

\section{HASIL DAN PEMBAHASAN}

Dari hasil kelas kesesuaian lahan diperoleh bahwa total lahan yang sesuai (S2) untuk tanaman Gambir seluas 40.717 ha atau $35 \%$ dari luas kelas kesesuaian lahan tanaman gambir di Papak Bharat. Pengertian kelas lahan sesuai (S2) mempunyai factor pembatas dan factor pembatas ini berpengaruh terhadap produktivitas memerlukan tambahan input (masukan) dan pembatas tersebut biasanya dapat diatasi oleh petani (Djaenudin et.al, 2000).

Kelas kesesuaian lahan sesuai bersyarat (S3) untuk tanaman Gambir di Pakpak Bharat seluas 23.975 ha atau 17,68 $\%$ dari jumlah kelas kesesuaian lahan tanaman Gambir di Pakpak Bharat. Kelas kesesuaian lahan sesuai bersyarat (S3) lahan mempunyai factor pembatas yang lebih berat dari S2 yang mempengaruhi produktivitas, memerlukan input lebih bayak dari lahan yang tergolong S2 dan untuk mengatasinya memerlukan modal tinggi serta perlu ikut campur pemerintah atau pihak swasta (Djaenudin et.al, 2000). Kelas kesesuian lahan tidak sesuai (N) tanaman Gambir di Pakpak Bharat seluas 71.456 ha atau 52,7 \% dari jumlah kelas kesesuaian lahan tanaman Gambir di Pakpak Bharat. Kelas kesesuian lahan tidak sesuai $(\mathrm{N})$, lahan yang tidak sesuai karena faktor pembatas yang sangat berat dan atau sulit diatasi (Djaenudin et.al, 2000). Kelas kesesuian lahan tanaman Gambir di Kabupaten Pakpak Bharat dapat dilihat pada tabel 4.

Tabel 4. Kelas kesesuaian lahan untuk tanaman Gambir di Kab. Pakpak Bharat

\begin{tabular}{|c|c|c|c|c|}
\hline No & Kelas & Faktor Pembatas & Luas Lahan (ha) & $\begin{array}{c}\text { Dalam persen } \\
(\%)\end{array}$ \\
\hline \multicolumn{5}{|c|}{ Lahan tergolong sesuai } \\
\hline 1 & S1 (sangat sesuai) & - & - & - \\
\hline 2 & S2 (sesuai) & eh & 9.523 & 7,02 \\
\hline 3 & S2 (sesuai) & $\mathrm{eh}, \mathrm{rc}$ & 480 & 0,35 \\
\hline 4 & S2 (sesuai) & eh, nr & 22.566 & 16,64 \\
\hline 5 & S2 (sesuai) & $\mathrm{nr}$ & 7.602 & 5,61 \\
\hline 6 & S3 (sesuai bersyarat) & eh & 14.257 & 10,51 \\
\hline 7 & S3 (sesuai bersyarat) & oa & 877 & 0,65 \\
\hline 8 & S3 (sesuai bersyarat) & tc & 4.836 & 3,57 \\
\hline 9 & S3 (sesuai bersyarat & tc, eh & 4.005 & 2,95 \\
\hline \multicolumn{5}{|c|}{ Lahan tergolong tidak sesuai } \\
\hline 10 & N (tidak sesuai) & eh & 37.205 & 27,44 \\
\hline 11 & $\mathrm{~N}$ (tidak sesuai) & eh, lp & 31.742 & 23,41 \\
\hline 12 & N (tidak sesuai) & $\operatorname{lp}$ & 2.509 & 1,85 \\
\hline & Junlah & & 135.602 & 100,00 \\
\hline
\end{tabular}

Sumber : BPTP Sumatera Utara, 2006

Keterangan : eh-bahaya erosi; nr-retensi hara; rc-kondisi perakaran; oa-keterbatasan oksigen; tc-ketinggian tempat; lp-penyiapan lahan 


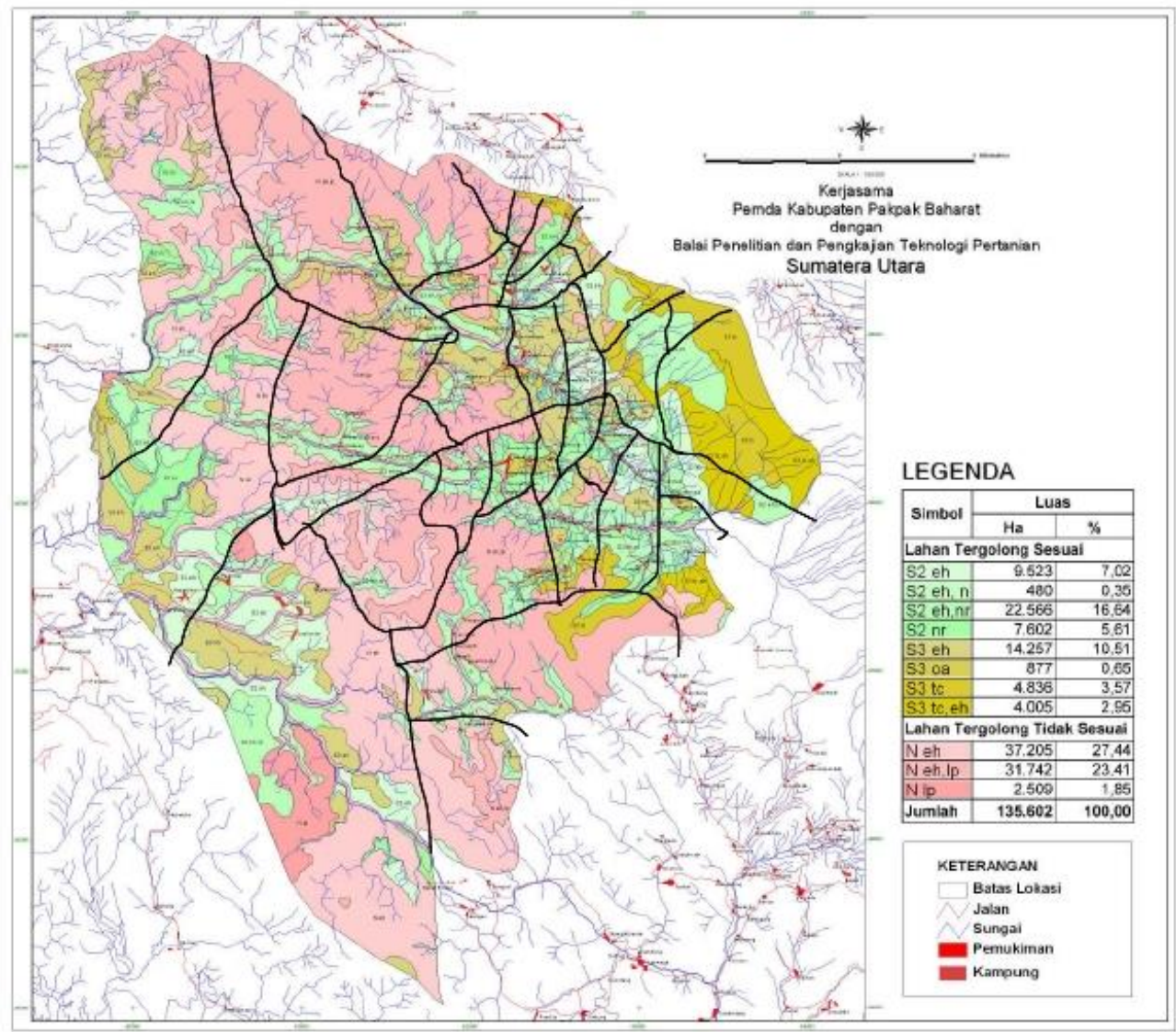

Gambar 1. Peta kesesuaian lahan komoditi Gambir

\section{SIMPULAN DAN SARAN}

Berdasarkan hasil pembahasan diperoleh bahwa kelas kesesuaian lahan sesuai (S2) seluas 40.717 ha atau $35 \%$, sesuai bersyarat (S3) seluas 23.975 ha atau $17,68 \%$ dan tidak sesuai $(\mathrm{N})$ seluas 71.456 ha atau 52,7 \% dari jumlah kelas kesesuaian lahan tanaman Gambir di Pakpak Bharat. Bahwa pengembangan tanaman Gambir di Kabupaten Papak Bharat masih sangat berpotensi. Jika dibandingkan luas penggunaan lahan yang eksis untuk gambir dengan luas lahan yang sesuai untuk Gambir maka masih ada potensi lahan pengembangan seluas 39.666 ha. Di samping itu masih tersedia juga lahan yang sangat luas yang dapat ditanami gambir dengan persyaratan teknologi budidaya tertentu.

\section{DAFTAR PUSTAKA}

Amien, I. 1996. Panduan Karakterisasi dan Analisis Zona Agro-Ekologi. Pembahasan Pemantapan Metodologi Karakterisasi Zona Agro-Ekologi. Badan Penelitian dan Pengembangan Pertanian, Puslttanak Bekerjasama dengan Proyek Pembinaan Kelembagaan Penelitian dan Pengembangan Pertanian, Pekanbaru.

Amien, I. Dan S Karama. 1993. Zona Agro-Ekologi dan Alternatif Pengembangan Pertanian Bul. Perhimpi 1(2) : 55-71.

Badan Pusat Statistik, 2013. Kabupaten Pakpak Bharat Dalam Angka. Badan Pusat Statistik Pakpak Bharat.

BPTP Sumatera Utara, 2006. Pewilayahan Komoditas Pertanian Skala 1 : 50.000 di Kabupaten Pakpak 
Bharat. Kerjasama Pemerintahan Kabupaten Pakpak Bharat dengan Balai Pengkajian Teknologi Pertanian Sumatera Utara. 71 hal.

Dhalami, A.,2006. Permasalahan Gambir

(Uncaria gambir Roxb.) di Sumatera Utara dan Alternatif Pemecahannya : 18-38.

Dinas Pertanian Kabupaten Pakpak Bharat, 2007. Budidaya Beberapa

Komoditas Tanaman di Kabupaten Pakpak Bharat. 118 hal.

Djaenudin, Marwan H., H. Subagyo, A. Mulyana dan N. Suharta. 2000. Kriteria Kesesuaian Lahan Untuk Komoditas Pertanian. Versi 3 : 313

Environmental System Research Institite.Inc, 1990. Uderstanding GIS. The ARC/INFO Method. California 92373, USA.

Ibrahim T.M., T. Marbun, E. Romjali, A.D. Harahap, A. Batubara, Nieldalina, S, Simatupang, A.J.
Harahap, M.A. Girsang, J. Sianipar, E. Sihite, M. Fadly dan Karmin. $1999 . \quad$ Sistem Pertanian dan Alternatif Komoditas Pertanian Arahan Berdasarkan Agroekologi di Sumatera Utara. JPPTP 1 (2) : 8194.

Puslittanak. 2000. Kriteria Kesesuaian Lahan untuk Komoditas Pertanian. Departemen Pertanian. Badan Penelitian dan Pengembangan Pertanian, Bogor. Versi 3.

Rossiter D.G. dan A.R.V. Wambeke, 1997. Automated Land Evaluation System ALES Version 4.65 User's Manual. Cornell University. Ithaca. NY USA. 